Jerzy Brzozowski (1)

Universidade Jaguelónica jerzy.brzozowski@uj.edu.pl

\title{
Presença de José Saramago na Polónia
}

\section{Resumo:}

A primeira obra de Saramago a ser publicada na Polónia não foi $O$ Memorial do Convento, cuja tradução tinha sido proposta às prestigiosas edições WL em 1988, mas $O$ Evangelho segundo Jesus Cristo, editado pela obscura SAWW e ignorado pela crítica. O Memorial do Convento foi impresso apenas em $1993 \mathrm{em}$ Londres; isto prova que a situação política continuava a influenciar a cultura polaca depois da queda do comunismo e da censura, nas condições do mercado livre. No entanto, a frieza dos polacos diante da obra de Saramago foi largamente compensada nos anos vindouros; todos os romances do Autor foram traduzidos para o idioma nacional, alguns até com 6 ou mais edições. O líder absoluto no mercado polaco é o Ensaio sobre a Cegueira, publicado 11 vezes por 3 editoras independentes. Este romance foi também o mais resenhado, porém, na crítica erudita surpreende o problema de uma certa obsessão por Deus nas obras daquele autor ateu, visível de maneira clara noutras obras como O Evangelho segundo Jesus Cristo ou Caim.

Palavras-chave: Saramago, receção, Polónia

\section{Abstract:}

\section{Saramago's presence in Poland}

Amazingly, the first novel of the Portuguese writer to be published in Poland was not Memorial do Convento, proposed to the well known WL Editions in 1988, but $O$ Evangelho Segundo Jesus Cristo, edited by an obscure publisher SAWW in 1991 and completely ignored by the critics. O Memorial do Convento was printed only in 1993 in London, and it shows the complicated, politically conditioned situation of the Polish culture after the breakdown of the communist rule in 1989. However, those mistakes were largely compensated afterwards: all Saramago's 
novels were translated to Polish, and some of them had 6 and more editions. The champion in the Polish market is undoubtedly $O$ Ensaio sobre a Cegueira, with 11 editions carried out by 3 different editors and preceded by two press "trailers". This novel also seems to be the favorite of the critics, yet, in the erudite studies prevail, curiously enough, the God obsession in other works of this atheist writer. Keywords: Saramago, reception, Poland

A primeira obra de Saramago publicada na Polónia, em 1991, foi o Evangelho segundo Jesus Cristo, editado pela obscura editora Kantor wydawniczy SAWW, sob o título Ewangelia Jezusa Chrystusa. O tradutor foi Cezary Długosz, tradutor juramentado de espanhol e português, também autor de dois manuais, do português básico Rozmówki portugalskie, e do espanhol básico, de quem se pode dizer: "um ilustre desconhecido", pois além da única tradução deste livro importante, nada consta sobre ele nos catálogos das maiores bibliotecas do país. O livro não teve nenhum sucesso na época ${ }^{1}$ : o número de artigos críticos na imprensa dos anos 1992-1994, segundo as fontes investigadas (nomeadamente a imponente Bibliografia zawartości czasopism, bibliografia das publicações da imprensa polaca) foi... zero ocorrências. Isto é insólito, já que, sem contar com as várias dezenas de revistas culturais e jornais de circulação pelo menos a nível regional, existe na Polónia desde 1949 a revista especializada Nowe książi, na qual se resenha via de regra qualquer publicação literária digna de atenção; todas as obras de Saramago publicadas na Polónia nos anos seguintes foram resenhadas naquela revista.

Contudo, na época em que a Polónia acabava de sair do sistema comunista, mudaram as expectativas do público, que desejava ler obras até então inacessíveis por motivo de censura, ou por direitos autorais difíceis de conseguir (tanto por causa de valores, como das reticências de autores e agentes "ocidentais", sobretudo americanos, a negociar com as editoras polacas pertencentes ao Estado comunista). Diante daquela

${ }^{1} \mathrm{O}$ que não significa que não tenha sido lido: conhecia-o Czesław Miłosz, que criticou amargamente o autor desde que se tornou pública a notícia sobre a outorga a José Saramago do Prémio Nobel. 
viragem política, e da mudança subsequente do mercado do livro, afinal privatizado, mudou tanto a demanda, como a oferta: de repente, quase desapareceu do mercado a literatura dos autores latinoamericanos e ibéricos $^{2}$ bem vistos pelo regime anterior, diminuiu também sensivelmente o número de obras dos autores franceses: os produtos culturais mais desejados passaram a ser os de proveniência norte-americana.

Por outro lado, naquela nova paisagem política qualquer crítica a respeito da Igreja católica era mal vista. Essas são as razões prováveis da demora na publicação do Memorial do Convento. Este livro tem uma história tragico-cómica na Polónia, pois o manuscrito da tradução elaborada por Elżbieta Milewska foi proposto à prestigiada editora Wydawnictwo Literackie já em 1988, a qual, devido a uma gestão incompetente, após a sua aceitação prévia, deixou de publicá-lo. O Memorial saiu pois, na tradução mencionada, em Londres [sic!], só em 1993, tendo depois 6 reedições na editora Rebis, no outono de 1998, em 2001, 2004, 2009, 2012 e 2017. Note-se, nesta ocasião, que esta obra foi objeto de pelo menos quatro artigos críticos sérios em 1998 e 1999, ou seja, logo após a sua publicação polaca. Porém, o êxito deste livro foi eclipsado pelo número das edições do Ensaio Sobre a Cegueira, que após a primeira publicação na editora Muza em 1999 foi reimpresso na mesma editora em 2002, reeditado na editora Świat Książki em 2000, e finalmente na editora Rebis em 2008, 2009, 2010, 2013, 2015, 2016, 2018, tendo logo em 1999 cinco resenhas na imprensa, tanto diária como erudita.

Em 1999, na editora Rebis, que desde aquele ano se torna quase monopolista no mercado polaco no que se refere à obra saramaguiana, saem Todos os nomes, na tradução de Elżbieta Milewska. A obra tem 3 reedições na mesma editora $(2003,2009,2015)$, curiosamente anunciadas na contracapa, "do Autor do Ensaio Sobre a Cegueira”. É, cabe notar, o último grande romance de Saramago traduzido para o polaco por Elżbieta Milewska, que publicará ainda apenas As pequenas memórias (2012) na editora Świat Książki. Isto pode surpreender, porque

2 Trato daquele problema no artigo "A presença da literatura portuguesa na Série Ibérica da editora Wydawnictwo Literackie”, a ser publicado em 2020. 
a tradutora saiu-se muito bem ${ }^{3}$ na dificílima tarefa de traduzir dois, se calhar, entre os mais valiosos romances do escritor.

As traduções das obras seguintes do nosso autor são o feito de Wojciech Charchalis, professor na Universidade de Poznań, cidade onde tem a sua sede também a editora Rebis, o que pode ter tido, ao início, certa importância. Hoje em dia, Charchalis é um tradutor conhecidíssimo, autor de mais de quarenta volumes traduzidos de espanhol e português, inclusive da nova tradução de Dom Quijote (2014) e da maioria da obra poética de Fernando Pessoa. Porém, em 2000, quando a Rebis publicou a sua tradução do Ano da Morte de Ricardo Reis, ele ainda estava no início da sua carreira, o que o próprio admite no seu prefácio, no qual agradece a ajuda, entre outros, da dra. Milewska e da sua esposa Maria Teixeira Dias Charchalis, assegurando todavia que assume a responsabilidade exclusiva pelos erros (os quais de facto não são poucos).

O livro foi reimpresso apenas em 2010, mas Charchalis trabalha rápido e em 2002 publica na editora Rebis História do Cerco de Lisboa (com a reedição em 2010), em 2003, A Jangada de Pedra (reedição em 2011), em 2005, O homem duplicado (reedição em 2011), em 2009 o Ensaio sobre a Lucidez: este último teve a única resenha da obra saramaguiana desfavorável ${ }^{4}$, titulada "Nieudana antyutopia noblisty" (A antiutopia mal-sucedida), o que decerto fez com que o livro não fosse reeditado. No ano da morte do escritor (2010) sai O Manual de Pintura e de Caligrafia e reeditam-se vários outros, sempre com o anúncio na contracapa: "do autor do Ensaio Sobre a Cegueira"... Vêm sucessivamente $A$ Viagem do Elefante (2012), Caim (2013) e As Intermitências da Morte (2018), sempre na tradução de Charchalis o qual se torna, de modo inquestionável, o tradutor "número um" de Saramago na Polónia.

3 Tive a ocasião de formar esta opinião orientando a dissertação de mestrado da Srta. Elwira Matluch (2009), Sobre a tradução polaca de aforismos, provérbios e expressões idiomáticas de 'Todos os Nomes' e de 'Memorial do Convento’ de José Saramago. Dissertação de mestrado [não publicada], Uniwersytet Jagielloński.

${ }^{4}$ Para este e outros artigos críticos publicados na imprensa polaca, cf. infra, a lista da bibliografia. 
Do mesmo modo, não se pode pôr em dúvida a primazia da editora Rebis, e mais ainda, do Ensaio Sobre a Cegueira, que na estratégia daquela editora, tornou-se uma "isca" para atrair novos leitores.

Diante do exposto, podemos perguntar: porquê tamanha popularidade desta obra, provavelmente preferida dos polacos? E como, finalmente, se apresenta a crítica das obras de José Saramago na Polónia, quem a escreve, e onde se publica?

A autora de um blogue chamada Alison faz a mesma pergunta e sugere que esta popularidade se deveria graças ao filme de Fernando Meirelles ${ }^{5}$... Uma resposta trivial e provavelmente errada, sendo que este filme não teve muito êxito na Polónia; tanto mais errada que a verdade às vezes parece mais trivial ainda. É que, poucos dias depois do anúncio do Prémio Nobel de Saramago, os dois principais diários do país, Gazeta Wyborcza e Rzeczpospolita, decidiram publicar trechos escolhidos de um romance saramaguiano. E - pasme-se - em ambos os casos tratava-se do mesmo livro, Ensaio Sobre a Cegueira, nas duas traduções concorrentes, de Elżbieta Milewska (Esej o ślepocie) e de Zofia Stanisławska, que lançará depois o título bem sucedido, Miasto ślepców (A cidade dos cegos). Mesmo hoje em dia, na era do declínio da imprensa clássica e da prevalência da internet, não se pode subestimar o impacto de tal coincidência; mas naquele tempo de internet ainda balbuciante, estes dois jornais eram os líderes absolutos do mercado: Gazeta Wyborcza tinha meio milhão de cópias vendidas e Rzeczpospolita, graças à sua política informativa prudente, gozava do status de órgão semi-oficial do governo. Assim sendo, toda a gente culta lia um ou outro destes jornais, a maioria os dois.

Agora bem, é interessantíssimo como pôde acontecer uma coincidência realmente tão insólita. Não tendo a possibilidade de esclarecer este tópico na sua fonte, vamos conjeturar: o redator do jornal, chamando uma especialista, no caso a Dra. Elżbieta Milewska, pergunta à

${ }^{5}$ [on-line] http://alison-2.blogspot.com/2012/09/miasto-slepcow_10.html -10.09 .2018 . 
tradutora: "qual é o melhor livro de Saramago?" Eis a resposta provável da tradutora: "é o Memorial do convento, a tradução polaca já foi publicada em Londres". “O que significa o título?”, pergunta o jornalista. "Literalmente memorial do convento, mas não é bem isso", responde a tradutora. Jornalista: "Não? E sobre o que afinal trata o livro?" Tradutora: "Bem, ele começa com um auto da fé em Lisboa..." Jornalista: “OK, este não queremos. Um outro?" Tradutora : "Há um outro que é uma parábola do totalitarismo, chama-se Ensaio Sobre a cegueira." Jornalista: "Ótimo, então, traduza umas 10 páginas deste aí".

Esta conversa fictícia não é tão ridícula quanto possa parecer: o autor do presente artigo conhece bem o mundo do livro e da imprensa, sendo um antigo profissional dos dois. Era bem assim que isto funcionava: acrescente-se que na época nenhum grande jornal do país teria ousado mostrar um anticlericalismo aberto, mesmo que a Gazeta Wyborcza hoje em dia já o faça, depois daqueles anos de abstinência. O motivo é bem claro: o Papa João Paulo II estava ainda vivo e uma ousadia assim não seria bem aceite pelo público da época. Por outro lado, era conhecida uma opinião favorável do grande escritor Gustaw Herling Grudziński a respeito do Ensaio Sobre a Cegueira que ele devia ter lido em italiano: somando tudo isto, o resultado foi aquele que nós conhecemos.

Passando à crítica do autor em polaco: o que salta aos olhos é a ausência total dos grandes nomes da nossa literatura entre os que a escrevem. Além de Herling Grudziński, falou um só, poeta e ganhador do Prémio Nobel Czesław Miłosz: mas a crítica dele a respeito de Saramago era arrasadora. Miłosz diz o seguinte: „É uma escrita que está na moda, ligeira, engraçada, mas finalmente sem graça, porque as suas piadas caem na trivialidade. Detesto este escritor" [trad. J.B.] ${ }^{6}$. Naquele tempo Czesław Miłosz era a segunda autoridade inteletual do

${ }^{6}$ O poeta ganhador do Prémio Nobel disse na entrevista ao diário Dziennik Polski, de 09 de outubro de 1998: „Jest to pisarstwo modne, dowcipne, ale ten dowcip pada 'na płask'. Przyznam się, że go nie znoszę." Vide: [on-line] https://dziennikpolski24.pl/nobel-dla-saramago/ar/1901474. 
país, logo após o Papa João Paulo II ; de modo que se Czesław Miłosz falou, estava falado.

Decerto, isto parece um pouco exagerado, mas na época, só em Cracóvia, viviam Szymborska (Prémio Nobel do ano 1996), Mrożek, Zagajewski; havia também Różewicz, Julia Hartwig, Ewa Lipska: todos eles se tinham calado. Dos escritores de certo prestígio, embora sendo de segundo escalão, só comentaram a obra de Saramago Paweł Huelle (2009) e Krzysztof Varga (2002), o que é pouco. A maioria dos outros autores das críticas na imprensa diária eram jornalistas, como Janusz Drzewucki, francamente um « fã » de Saramago, que nas suas quatro resenhas comentou o Ano da morte de Ricardo Reis, Todos os nomes, a Jangada de pedra e o Homem duplicado, o que é uma prova de bom gosto, mas trata-se de pouco mais que resumos. Na minha opinião, vale a pena lembrar que o vencedor do Prémio Nobel de 1997 foi Dario Fó, o que o nosso establishment literário recebeu muito mal: assim sendo, o galardão para o comunista e anticlerical Saramago podia parecer a alguns outra provocação do júri de Estocolmo.

Por outro lado, tem razão Wojciech Charchalis quando diz em 2013 que se escreveu na Polónia a respeito de Saramago muitas inverdades e tolices ${ }^{7}$. Explorou-se o lado sensacionalista da figura dele, como atestam os títulos de várias entrevistas: „Eu era o favorito” (1998a) é o mais inofensivo, mas há outros: „A democracia é mentira: a confissão de um comunista” [2006]; „Vivemos o tempo do apocalipse” (2004); „Um comunista de hormónios” (2008); „O planeta para os ricos” (1998b); ou enfim: „Mas sim, eu sou grosseiro!” (2008). Ora, a Polónia na década dos anos 1990 vivia um período de fé neoliberal e tudo isto não agradava ao mainstream; inclusive os intelectuais na sua maioria aceitaram esta obediência.

$\mathrm{O}$ auge parece-me o artigo de Artur Domosławski na Gazeta Wyborcza: „O Pepe fala como o papa”, de 2002. Este artigo mereceu uma violenta polémica da revista de direita Fronda, que quebrou o consenso

7 „Niemniej na temat José Saramago napisano wiele rzeczy niepoważnych i nieprawdziwych, a wygląda na to, że część z nich zadomowiła się w naszej przestrzeni na stałe" (Charchalis, 2013: 9). 
tácito de silêncio; vale a pena citar pelo menos o título pitoresco: „Lenin Guevara I', o papa do ressentimento" (2002). Assim sendo, não deve surpreender que a Jangada de Pedra não tivesse originado muita reflexão na imprensa polaca (apenas duas resenhas, uma do 'fan' do Autor, Drzewucki, e outra, em Nowe książki: é pouco), mesmo que a data da sua publicação (2003) convirja com a entrada da Polónia na União Europeia: parece que Saramago é considerado pelo nosso público como um grande estilista, um contador de estórias fascinante e um grande humanista, a quem se deve apenas perdoar as convicções políticas estranhas ${ }^{8}$.

Mas há também o que se pode chamar de crítica erudita, ou seja, a dos universitários que publicam na imprensa semanal ou mensal. Parece que o autor da presente inaugurou esta série em 18 de outubro de 1998 com o artigo "Nobel dla Portugalii" (o Prémio Nobel para Portugal) na revista Tygodnik Powszechny, naquele tempo talvez a mais influente do país. O dito artigo, além da apresentação do próprio escritor, praticamente desconhecido na Polónia, continha um esboço da poética da sua prosa e uma análise sucinta do Memorial do Convento, que me tinha encantado, e do Evangelho segundo Jesus Cristo, que critiquei com convicção, e não desminto esta avaliação, embora a frase final, em que dizia que "teria preferido que o prémio fosse outorgado a Vergílio Ferreira" não resista mais à crítica.

A Profa. Anna Kalewska, então jovem doutora, já uma semana antes tinha publicado na Gazeta Wyborcza um artigo sob o título intrigante "Chwast Historii" (Erva daninha da história) que aludia ao sobrenome do escritor e depois a tradução do discurso de Estocolmo do laureado. Porém, o que merece atenção é o seu extenso artigo na revista mensal Twórczość , muito prestigiada, em que apresentava uma análise da obra saramaguiana mais amadurecida, tendo tido mais algum tempo para ler e ruminar aquilo que foi publicado a respeito do autor. $\mathrm{O}$ artigo intitulava-se „O humanismo e ironia de José Saramago” e citando-me inclusive, fornecia uma visão um pouco diferente da minha, mais

${ }^{8}$ Cf. um título na imprensa: „Dobry pisarz, choć komunista...” (Bom escritor, mesmo que comunista, Magierowski, 2008). 
compreensível a respeito do livro mais controvertido; mas também lançava a frase que define o autor como „descrente, mas não ateista, como ele próprio admite", que se mostrou realmente digna de atenção, o que me permito comentar adiante.

Vale a pena destacar também o artigo de Elżbieta Milewska, em Wiedza i życie (Milewska, 1998), e dois artigos na revista Znak, pertencente ao mesmo grupo editorial que o Tygodnik Powszechny, da autoria de Nina Pluta, que fazia uma análise entusiasta do Memorial do convento e bastante menos entusiasta do Ensaio Sobre a Cegueira. A autora comentava no fim: „Em certos momentos, onde a alegoria cobre a parte emocional, alguns tópicos parecem-nos demasiadamente unívocos, ou até banais, como aquele da cegueira simbólica da humanidade, a figura simbólica da mulher-guia, a descoberta dos instintos imemoriais [...] o romance salva-se graças à pujança artística do elemento verbal" (Pluta, 1999, trad. J.B.). Outra resenha desta autora era consagrada a Todos os nomes que Nina Pluta, a despeito de várias páginas consagradas ao romance, subestimou, no meu entender, focando-se na construção alegórica do livro (que considero uma simplificação indevida). Próximo da crítica erudita e académica situa-se o prefácio de Wojciech Charchalis ao volume Świat powieści José Saramago (O universo da prosa de José Saramago, Poznań, 2013), já citado.

$*$

Finalmente deve-se passar à crítica estritamente académica da obra do autor, que nos reserva algumas surpresas. A primeira é que no volume dirigido por Charchalis, ao qual acabo de aludir, participam, além do próprio Charchalis e de Ewa Łukaszyk, seis outros estudiosos dos quais nenhum é especialista de filologia portuguesa: são filósofos, antropólogos de cultura, polonistas, ou seja - Saramago na pesquisa universitária passa a interessar não somente aos especialistas de literatura portuguesa: a obra dele é agora alvo de comentários de pesquisadores representando disciplinas bem variadas, como teóricos de literatura ou teólogos. Outros exemplos disso, mais recentes, seriam um capítulo do livro de Joanna Ślósarska, de 2016, tratando do Manual de Pintura e Caligrafia, e o artigo consagrado ao Evangelho segundo Jesus Cristo 
por Sławomir Bobowski (2016) na revista da Universidade Católica de Lublin Ethos: o artigo nas suas conclusões não deixa de criticar a visão do cristianismo representada por Saramago, mas mesmo assim, o próprio facto de o artigo sair naquela revista, quebrando o tabu do silêncio, é uma novidade, mostrando definitivamente que a crítica política superficial do nosso autor já não se pratica.

Isto com certeza é, em parte, mérito de Ewa Łukaszyk, nossa ex-colega da Universidade Jagellónica, que se tornou a mais competente e assídua leitora da obra de Saramago na Polónia. Além de vários artigos, inclusive na obra Świat powieści Saramago (2013), já citada, destacam-se dois livros seus, cujos títulos podem ser traduzidos como O nomadismo como a solução da crise do Mundo contemporâneo na escrita de José Saramago, de 2005, e O império e a saudade. O estilo tardio na cultura portuguesa, de 2015, onde Saramago é também o protagonista principal.

Terminemos o presente artigo com algumas das conclusões do meu parecer no concurso da Sra. Łukaszyk para o título de professora catedrática, que aludem ao primeiro destes volumes:

O que pode surpreender os que tenham conhecimento apenas superficial da obra do Saramago é a posição central de Deus na sua escrita. Um marxista com a obsessão de Deus? Parece que sim: como escreve a autora, trata-se de "um ateismo que não decorre da ignorância ou descrença na existência da divindade, mas da rejeição consciente, da recusa de aceitar a ideia imposta" (Łukaszyk, 2005: 19, trad. J.B.). Não se trata apenas do controvertido Evangelho segundo Jesus Cristo; o tema de Deus (ou seja: do absoluto, e da racionalidade deste Mundo) é presente e desenvolvido, como mostra Łukaszyk, em Memorial do convento, Todos os nomes, O ensaio da cegueira, História do cerco de Lisboa, de modo especial em Levantado do chão e a Jangada de pedra [observemos que Caim ainda não tinha sido publicado naquela altura].

Eis mais alguns trechos da sua obra (Łukaszyk, 2005: 336-337, trad. J.B.): 
Sapando as raízes cristãs e gregas da nossa cultura, deixa o homem completamente despojado, sendo que o seu deserto não é repleto de valores novos, capazes de fundamentar sua vida espiritual. E uma tentativa arriscada de deixar a civitas, no seu entender caindo na ruína [...].

Porém, na opinião final da autora (Łukaszyk, 2005: 343, trad. J.B.): à tentação de ruptura anunciada na Jangada de pedra precisa-se opor o apelo de fidelidade a esta Europa como sede de civilização e declarar novamente o valor do europocentrismo tão continuamente e ardorosamente criticado. Sobretudo porque, na cidade ou no deserto, cada eu fica inexoravelmente no centro do seu próprio horizonte. Independentemente de quanto desejarmos ser Outro, podemos ser apenas nós próprios.

O outro livro de Ewa Łukaszyk (2015) tenta pôr em questão as conclusões expostas acima, decerto, em parte, sob o impacto da leitura de Caim. A solução, no seu entender, seria o projeto utópico de transculturalidade, elaborado sob auspícios de Jacques Derrida e Giorgio Agamben; mas, à tentação daquela abertura diferindo sempre uma opinião declarada, mesmo que fascinante, o autor deste artigo prefere outra tentação, a de terra firme desta Europa, onde ainda "podemos ser apenas nós próprios".

\section{Referências bibliográficas}

\section{Bibliografia ativa:}

\section{A. Livros do Autor publicados em polaco}

SARAMAGO, J. (1992), Ewangelia wedtug Jezusa Chrystusa (O Evangelho segundo Jesus Cristo, 1991), trad. Cezary Długosz, SAWW, Poznań; Rebis, Poznań, 2011, 2017.

SARAMAGO, J. (1993), Baltazar i Blimunda (Memorial do Convento, 1982), trad. Elżbieta Milewska, Puls, London; Rebis, Poznań, 1999, 2001, 2004, 2009, 2012, 2017. 
SARAMAGO, J. (1999), Miasto ślepców (Ensaio Sobre a Cegueira, 1995), trad. Zofia Stanisławska, Muza, Warszawa, 1999, 2002; Świat Książki, Warszawa, 2000; Rebis, Poznań, 2008, 2009, 2010, 2012, 2013, 2015, 2016, 2018.

SARAMAGO, J. (1999), Wszystkie imiona (Todos os Nomes, 1997), trad. Elżbieta Milewska, Rebis, Poznań, 1999, 2003, 2009, 2015.

SARAMAGO, J. (2000), Rok śmierci Ricarda Reisa (O Ano da Morte de Ricardo Reis, 1984), trad. Wojciech Charchalis, Rebis, Poznań, 2000, 2010.

SARAMAGO, J. (2002a), Kamienna tratwa (A Jangada de Pedra 1986), trad. Wojciech Charchalis, Rebis, Poznań, 2002, 2003, 2011.

SARAMAGO, J. (2002b), Historia oblężenia Lizbony (História do Cerco de Lisboa, 1989), trad. W. Charchalis, Rebis, Poznań, 2002, 2010.

SARAMAGO, J. (2005), Podwojenie (O Homem Duplicado, 2002), trad. Wojciech Charchalis, Rebis, Poznań, 2005, 2011.

SARAMAGO, J. (2009), Miasto biatych kart (Ensaio Sobre a Lucidez), trad. Wojciech Charchalis, Rebis, Poznań.

SARAMAGO, J. (2010), O malarstwie i kaligrafii (Manual de Pintura e Caligrafia, 1977), trad. Wojciech Charchalis, Rebis, Poznań.

SARAMAGO, J. (2012a), Podróż stonia (A Viagem do Elefante, 2008), trad. Wojciech Charchalis, Rebis, Poznań.

SARAMAGO, J. (2012b), Mały pamiętnik (As Pequenas Memórias, 2006), trad. Elżbieta Milewska, Świat Książki, Warszawa.

SARAMAGO, J. (2013), Kain (Caim, 2009), trad. Wojciech Charchalis, Rebis, Poznań.

SARAMAGO, J. (2018), Rozterki śmierci (As intermitências da morte, 2005), trad. Wojciech Charchalis, Rebis, Poznań.

\section{B. Obras e fragmentos das obras do autor publicados na imprensa polaca}

SARAMAGO, J. (1998a), „Esej o ślepcach” (fragmento do Ensaio Sobre a Cegueira), trad. Zofia Stanisławska, Gazeta Wyborcza, 237/1998

SARAMAGO, J. (1998b), „Esej o ślepcach” (fragmento do Ensaio Sobre a Cegueira), trad. Elżbieta Milewska, Rzeczpospolita, 237/1998

SARAMAGO, J. (1998c), "Spod figowego drzewka: o tym, jak bohater literacki stał się mistrzem, a autor jego uczniem" (palestra proferida em 
Estocolmo na entrega do Prémio Nobel), trad. Anna Kalewska, Gazeta Wyborcza, 291/1998.

SARAMAGO, J. (2003), „Kamienna tratwa” (fragmento da Jangada de Pedra), Twórczość, 9/2003.

\section{Entrevistas com José SARAMAGO na imprensa polaca}

SARAMAGO, J. (1998a), "Byłem faworytem" (Eu era o favorito), J. S. Entrevistado por Łukasz Gołębiowski, Rzeczpospolita 237/1998

SARAMAGO, J. (1998b), "Planeta dla bogaczy" (O Planeta para os ricos), J. S. entrevistado por Łukasz Gołębiewski, Magazyn Literacki, 4/1998.

SARAMAGO, J. (2004), “Żyjemy w czasach apokalipsy” (Vivemos no tempo do Apocalipse), J.S. entrevistado por Małgorzata Brączyk, Przegląd, 46/2004, Warszawa.

SARAMAGO, J. (2006), “Demokracja jest kłamstwem. Spowiedź komunisty" (A democracia é uma mentira. Confissão de um comunista), J.S. entrevistado por Didier Jacob, Forum, 47/2006.

SARAMAGO, J. (2008), “Co tam, ja jestem gruboskórny! Wieczny prowokator" (Mas quê! Eu sou grosseiro! Um eterno provocador), J.S. entrevistado por Evelyn Finger, Forum, 50/2008.

SARAMAGO, J. (2008), „Komunista hormonalny” (Um comunista de hormónios), J.S. entrevistado por Marta Strzelecka, Gazeta Wyborcza $73 / 2009$.

\section{Bibliografia passiva:}

\section{A. Revistas e jornais}

BATOR, J. (2013), „W cieniu słonia” (resenha da Viagem do Elefante), Tygodnik Powszechny, 20/2013, Dod. Książki w Tygodniku.

BOBOWSKI, S. (2016), „Jezus odmitologizowany? Antyewangelia według José Saramago", Ethos, 4/2016, Lublin.

BRZOZOWSKI, J. (1998), „Nobel dla Portugalii”, Tygodnik Powszechny, no $42,18.10 .1998$.

CHROMIK, E. (2009), „Kaprawe oczy strachu” (sobre Ensaio da Cegueira), Śląsk, 9/2009. 
DOMOSŁAWSKI, A. (2002), „Pepe mówi jak Papież”, Gazeta Wyborcza, $52 / 2002$.

DRZEWUCKI, J. (2000), „Wszystkie imiona” (Todos os Nomes), Rzeczpospolita, 27/2000, E5.

DRZEWUCKI, J. (2001), „Rok śmierci Ricarda Reisa”, Rzeczpospolita, 29/2001, D3.

DRZEWUCKI, J. (2004), „Kamienna tratwa” (Jangada de Pedra), Rzeczpospolita, 91/2004, A8.

DRZEWUCKI, J. (2006), „Ja, twój sobowtór”, Twórczość, 1/26.

HUELLE, P. (2009), "Trzy miasta, trzy arcydzieła" (sobre o Ano da Morte de Ricardo Reis), Przeglad Polityczny 93/2009, Gdańsk.

GRZYMISŁAWSKI, Ł. (2005), „Dwóch to zbyt wiele” (resenha do livro Homem Duplicado), Gazeta Wyborcza, 73/2005.

JANKOWICZ, G. (2010), „Ewangelia sprzeciwu”, Tygodnik Powszechny, 26/2010, Dod. Książki w Tygodniku.

JANKOWICZ, G. (2013), „Piętno”, resenha de Caim, Tygodnik Powszechny, 49/2013, Dod. Książki w Tygodniku.

KALEWSKA, A. (1998), „Chwast historii”, Gazeta Wyborcza, 289/1998.

KALEWSKA, A. (1999), „Humanizm i ironia”, Twórczość, 1/1999.

KALEWSKA, A. (2010), „Camões, Pessoa, Saramago i inni...”, Między Oryginałem a Przekładem: Strategie wydawców, strategie pisarzy, Kraków.

MAGIEROWSKI, M. (2008), „Dobry pisarz, choć komunista”, Rzeczpospolita, 16.05.2008.

MARZEC, B. (2010), „Surowy krytyk cywilizacji”, Rzeczpospolita, 241/2010.

MILEWSKA, E. (1998), „Ensaio sobre a Cegueira - recenzja” Rzaczpospolita, 238/1998.

MILEWSKA, E. (1999), „Rok chwały José Saramago”, Wiedza i życie, 4/1999.

MIŁKOWSKI, M. (2005), „Świat ludzi potulnych” (resenha do livro Podwojenie), Tygodnik Powszechny, 29/2005.

PLUTA, M. (2001), „Ponad lśniącym morzem bieli: wokół Miasta Ślepców”, Fraza, 3/2001. 
PLUTA, N. (1999), „Baltazar i Blimunda”; “Miasto ślepców” (resenhas), Znak, 12/1999.

PLUTA, N. (2000), „Wszystkie imiona” (resenha de todos os Nomes), Znak, $7 / 2000$.

RADZISZEWSKI, S. (2015), „Lepiej nie wi(e)dzieć, czyli miasto bez imienia: José Saramago i jego apokaliptyczna wizja ludzkości”, Studia Teologiczne, Białystok, t. 33 (2015).

RODRIGUES PEREIRA, N. (2002), „Lenin Guevara I, papież resentymentu", Fronda, no 27/28, Warszawa.

TCHÓRZEWSKI, A. (1999), „Baltazar i Blimunda - recenzja”, Magazyn Literacki, 1/1999, Warszawa.

VARGA, K. (2002), „Historia oblężenia Lizbony. Recenzja”, Gazeta Wybor$c z a, 62 / 2002$, dod. Magazyn nr 11, Warszawa.

WAPIŃSKA, M. (2009), „Nieudana antyutopia noblisty” (resenha do livro Miasto biatych kart), „Dziennik Gazeta Prawna”, 195/2009, A16, Warszawa.

WAPIŃSKA, M. (2010), „Od rzemieślnika do artysty” (resenha do livro O Manual da Pintura e Caligrafia), Dziennik Gazeta Prawna, 182/2010, dod. Kultura, Warszawa.

\section{B. Revista especializada Nowe Ksiażki}

CHMIELEWSKA, J. (2013), „Sulejman w drodze do Wiednia”, 2/2013.

KOMOROWSKI, A. (1999), "Miasto ślepców”, 7/1999.

KOMOROWSKI, A. (2011), „Kwestia smaku”, 1/2011.

KOMOROWSKI, A. (2013), „Dzieciństwo noblisty”, 1/2013.

PIETRZAK, P. (2004), „Kamienna tratwa”, 3/2004.

PIECZARA, M. (2000), „Wszystkie imiona”, 6/2000.

PIECZARA, M. (2002), „Historia oblężenia Lizbony - recenzja”, 5/2002.

SCHEFS, M. (2005), „Sobowtóry”, 9/2005.

SCHEFS, M. (2005), „Początek i koniec ludzkości”, 1/2014.

SIKORA, A. (2010), „Biała ślepota II”, 1/2010.

ZIELIŃSKI, J. (2001), „Rok śmierci Ricardo Reisa”, 5/2001. 


\section{Obras académicas}

CHARCHALIS, W. (ed.) (2013), Świat powieści Saramago, Wydawnictwo UAM, Poznań.

ŁUKASZYK, E. (2005), Pokusa pustyni. Nomadyzm jako wyjście z kryzysu wspótczesności w pisarstwie José Saramago, Universitas, Kraków.

ŁUKASZYK, E. (2016), Imperium i nostalgia. „Styl późny” w kulturze portugalskiej, Wydawnictwo DiG, Warszawa.

MALTLUCH, E. (2009), Sobre a tradução polaca de aforismos, provérbios e expressões idiomáticas de 'Todos os Nomes'e de 'Memorial do Convento de José Saramago.' Dissertação de mestrado [não publicada], Uniwersytet Jagielloński.

ŚLÓSARSKA, J. (2016), Poetyka tektoniczna, Primum Verbum, Łódź. 